\title{
Hepatitis B vaccine and NK cells: a new player in memory
}

\author{
Maike Hofmann $\odot$ 1,2 Robert Thimme $\odot$ 1,2
}

Hepatitis B is a major global health burden caused by the HBV. Infection with HBV induces a necro-inflammatory liver disease and can either be self-limiting or persisting. Persisting or more precisely chronic HBV infection can progress to liver cirrhosis, end-stage liver disease and even liver cancer and thus results in an increased risk of dying prematurely. An effective and safe vaccine is available that confers over $95 \%$ protection by eliciting an immune response against the surface antigen of $\mathrm{HBV}$ (HBsAg). Indeed, a protective adaptive memory response mediated by memory $\mathrm{T}$ cells, memory B cells and anti-HBsAg antibodies is detectable on Hepatitis B vaccination. $^{1}$

Generally, current vaccination strategies target the adaptive arm of the immune system exploiting its capacity to establish a long-lasting protective immunological memory. However, it is becoming increasingly clear that not only the adaptive immune cells, the B and T cells, adapt their function on pathogen encounter to mediate protection on reinfection but also the innate immune system is able to establish a memory state that is called 'trained immunity' or 'innate memory'. For example, natural killer (NK) cells are innate cytotoxic lymphocytes that are important in the early immune response towards viral infections and can mediate trained rather unspecific immunity or even specific innate immune memory responses on re-challenge. ${ }^{3}$ However, only very little is known about the role of trained or innate memory immunity in vaccination, more specifically about memory NK cells. ${ }^{4}$

In Gut, Wijaya et $a l^{5}$ now report the emergence of a memory NK-cell response after hepatitis B vaccination. The authors compared NK-cell responses of 20 healthy individuals without a previous $\mathrm{HBV}$ infection, including 12 vaccinated and 8 non-vaccinated individuals. Functional, phenotypic and transcriptomic analyses of the respective NK-cell response were

${ }^{1}$ Department of Internal Medicine II, Freiburg University Hospital, Freiburg, Baden-Württemberg, Germany

${ }^{2}$ Faculty of Medicine, University of Freiburg, Freiburg im Breisgau, Baden-Württemberg, Germany

Correspondence to Dr Maike Hofmann, Internal Medicine II, Freiburg University Hospital, Freiburg 79106, Baden-Württemberg, Germany;

Maike.Hofmann@uniklinik-freiburg.de performed by applying flow cytometry, ELISA and single-cell RNA sequencing technologies. In addition, NK-cell responses of 10 chronically HBV-infected patients with low viral loads were assessed.

NK cells from vaccinated compared with non-vaccinated individuals exhibited increased degranulation and proliferation following cocultivation with autologous monocyte-derived dendritic cells pulsed with HBsAg that is included in the hepatitis $B$ vaccine. This was not the case after a respective re-exposure to the hepatitis $B$ core antigen ( $\mathrm{HBcAg}$ ) that is not part of the hepatitis $B$ vaccine (figure 1). These data clearly indicate an antigen-specific NK-cell memory response after hepatitis $B$ vaccination. The activating NK-cell receptor NKG2D and its stress-induced ligand ULBP-1, an unconventional major histocompatibility complex class I (MHCI)-like molecule, are shown to be important in mediating this NK-cell memory response after Hepatitis B vaccination. Still, the exact mechanism of the observed HBsAg-specific response remains open. Antiviral NK-cell memory has been best described in the context of cytomegalovirus infection. ${ }^{6}$ Here, it has been demonstrated that the recognition of viral UL40 peptides together with the non-classical MHC-I molecule HLA-E by the activating receptor NKG2C drives the clonal expansion of memory-like NKG2C+ NK cells. ${ }^{7}$
Future studies are required to unravel whether similar mechanisms are involved in the HBsAg-specific NK-cell memory response or whether hepatitis B vaccination increases an HBsAg-triggered stress response leading to NK-cell stimulation via the NKG2D/ULBP-1 axis.

Wijaya et $a l^{5}$ identify the inhibitory receptor KLRG1 and not NKG2D as a marker molecule of NK cells that potentially mediate the observed HBsAgspecific cytotoxic NK-cell response challenging the role of the NKG2D/ ULBP-1 axis in driving the emergence of a distinct NK-cell memory population after Hepatitis B vaccination. KLRG1+ NK cells in hepatitis B-vaccinated individuals are characterised by a mature effector phenotype with a high capacity to degranulate as a surrogate for cytotoxicity. This is in line with a previous study showing that KLRG1 + compared with KLRG1NK cells in humans exhibit an enhanced degranulation capacity. ${ }^{8}$ However, interferon gamma (IFN $\gamma$ ) production was not increased in KLRG1+ versus KLRG1NK cells after target cell stimulation in this study. ${ }^{8}$ Thus, this may explain the observation by Wijaya et $a l^{5}$ that the HBsAg-specific NK-cell memory response mediated by KLRG1+ NK cells after hepatitis $\mathrm{B}$ vaccination is not detectable on the level of IFN $\gamma$ secretion.

Of note, Wijaya et $a l^{5}$ also report that $\mathrm{HBsAg-specific} \mathrm{NK-cell} \mathrm{responses} \mathrm{in}$ chronically HBV-infected patients are similarly enhanced compared with hepatitis B-vaccinated individuals. In contrast to hepatitis B vaccination, an enhanced NK-cell response after $\mathrm{HBcAg}$ re-exposure is generated in chronic HBV infection
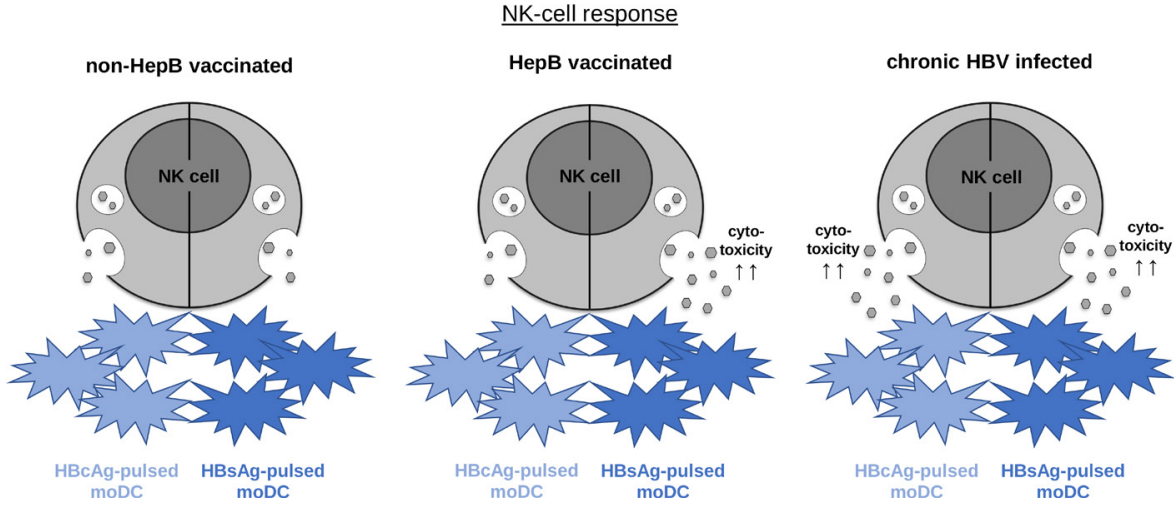

Figure 1 Hepatitis B virus (HBV) antigen-specific NK-cell responses in hepatitis B (HepB)vaccinated individuals and patients chronically infected with HBV. Increased degranulation of natural killer (NK) cells is detectable on stimulation with HBsAg-pulsed monocyte-derived dendritic cells (moDC) after HepB vaccination and in chronic HBV infection. HBcAg-pulsed moDCs, however, only mediate an enhanced degranulation of NK cells obtained from chronically HBV-infected patients. This probably reflects different antigen exposure in HepB vaccination versus chronic HBV infection. 
reflecting the differences in antigen exposure and thus further supporting the antigen-specific nature of the enhanced NK-cell response (figure 1). Importantly, this finding also uncovers a potential major difference between innate memory NK-cell and adaptive memory T-cell responses as functionality per se and also the memory establishment of $\mathrm{T}$ cells are impaired in chronic HBV and even generally in chronic viral infection. ${ }^{910}$ However, to further confirm that HBV antigenspecific NK-cell responses are indeed not affected by chronic HBV infection a more comprehensive analysis including resolved HBV infection is required.

In summary, the study by Wijaya et $a l^{5}$ highlights that hepatitis B vaccination not only induces adaptive immune memory but also trains the NK-cell response. This finding provides new insights into the immunity generated by hepatitis B vaccination and therefore into the modes of action of vaccines in general. In addition, the fact that the HBV antigen-specific NK-cell response is similarly enhanced in chronic HBV infection compared with hepatitis $B$ vaccination renders the NK-cell response an attractive target for novel treatment strategies in HBV cure. Hence, trained or innate memory NK-cell responses should be considered in the design of vaccines and immunotherapies in the context of viral infections.

Contributors MH and RT wrote the manuscript.
Funding The authors acknowledge support by the German Research Foundation (DFG; grant CRC1160IMPATH project A02).

Competing interests None declared.

Patient consent for publication Not required.

Provenance and peer review Commissioned; internally peer reviewed.

\section{(2) OPEN ACCESS}

Open access This is an open access article distributed in accordance with the Creative Commons Attribution Non Commercial (CC BY-NC 4.0) license, which permits others to distribute, remix, adapt, build upon this work non-commercially, and license their derivative works on different terms, provided the original work is properly cited, appropriate credit is given, any changes made indicated, and the use is non-commercial. See: http:// creativecommons.org/licenses/by-nc/4.0/.

(c) Author(s) (or their employer(s)) 2021. Re-use permitted under CC BY-NC. No commercial re-use. See rights and permissions. Published by BMJ.

$$
\text { (D) Check for updates }
$$

To cite Hofmann M, Thimme R. Gut 2021;70:229-230.

Received 4 May 2020

Revised 26 June 2020

Accepted 27 June 2020

Published Online First 15 July 2020

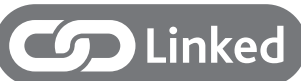

- http://dx.doi.org/10.1136/gutjnl-2019-319252

Gut 2021;70:229-230.

doi:10.1136/gutjnl-2020-321151
ORCID iDs

Maike Hofmann http://orcid.org/0000-0001-84108833

Robert Thimme http://orcid.org/0000-0003-1417-4135

\section{REFERENCES}

1 Banatvala J, Van Damme P, Oehen S. Lifelong protection against hepatitis $B$ : the role of vaccine immunogenicity in immune memory. Vaccine 2000;19:877-85.

2 Netea MG, Joosten LAB, Latz E, et al. Trained immunity: a program of innate immune memory in health and disease. Science 2016;352:aaf1098.

3 Paust S, Blish CA, Reeves RK. Redefining memory: building the case for adaptive NK cells. J Virol 2017;91. doi:10.1128/JVI.00169-17. [Epub ahead of print: 15 Oct 2017]

4 Sun JC, Lanier LL. Is there natural killer cell memory and can it be harnessed by vaccination? NK cell memory and immunization strategies against infectious diseases and cancer. Cold Spring Harb Perspect Biol 2018;10. doi:10.1101/cshperspect. a029538. [Epub ahead of print: 01 Oct 2018].

5 Wijaya RS, Read SA, Truong NR. Hbv vaccination and HBV infection induces HBV-specific natural killer cell memory. Gut 2021;70:357-69.

6 Cerwenka A, Lanier LL. Natural killer cell memory in infection, inflammation and cancer. Nat Rev Immunol 2016;16:112-23.

7 Hammer Q, Rückert T, Borst EM, et al. Peptide-Specific recognition of human cytomegalovirus strains controls adaptive natural killer cells. Nat Immunol 2018;19:453-63.

8 Schwartzkopff S, Gründemann C, Schweier O, et al. Tumor-Associated E-cadherin mutations affect binding to the killer cell lectin-like receptor $\mathrm{G} 1$ in humans. J Immunol 2007;179:1022-9.

9 Bertoletti A, Ferrari C. Adaptive immunity in HBV infection. J Hepatol 2016;64:S71-83.

10 Hofmann M, Wieland D, Pircher H, et al. Memory vs memory-like: The different facets of $\mathrm{CD}^{+}$ T-cell memory in HCV infection. Immunol Rev 2018;283:232-7. 